\title{
LOS REFUGIADOS CHILENOS RESIDENTES EN ARGENTINA COMO UN "PROBLEMA DE SEGURIDAD NACIONAL”, 1973-1983
}

\section{Chilean refugees residing in Argentina as a "national security problem", 1973-1983}

\author{
María Cecilia Azconegui*
}

\begin{abstract}
RESUMEN
El derrocamiento de Salvador Allende, y la posterior instauración de una dictadura militar en Chile tuvieron amplias repercusiones en el complejo escenario político argentino que se vio desbordado por la llegada de los exiliados. Si bien el gobierno no estaba preparado para esta situación, el acuerdo entre la Dirección Nacional de Migraciones (DNM), el Alto Comisionado de las Nacionales Unidas para los Refugiados (ACNUR) y las iglesias cristianas, hizo posible la creación de una red nacional que asistió a miles de chilenos. Este artículo analiza los cambios en las percepciones y las políticas gubernamentales con respecto a estos refugiados en el período 1973-1983. Se argumenta que, en un proceso complejo, marcado por ambigüedades y contradicciones que incluyó tanto instancias de integración como de rechazo, la progresiva ascendencia de la perspectiva de la seguridad nacional en la dirigencia de los sucesivos gobiernos motivó que los chilenos, bajo protección del ACNUR, fueran paulatinamente considerados una amenaza cuya permanencia en Argentina debía ser objeto de regulación, control, y, en casos puntuales, represión, eliminación física y/o expulsión. La presencia estatal dentro de la red humanitaria que los protegía hizo que los refugiados estuvieran más expuestos y su situación fuera de mayor vulnerabilidad que la de los exiliados que se habían mezclado con la población migrante. En contrate, cuando el conflicto del Beagle planteó un nuevo escenario en el que la chilenidad escaló posiciones en el orden de las amenazas, los protegidos del ACNUR fueron los chilenos menos afectados por el accionar represivo.
\end{abstract}

* Doctoranda en Historia. Docente e investigadora en la Facultad de Humanidades de la Universidad Nacional del Comahue-Cehepyc-Argentina. E-mail: cazconegui@gmail.com 
Palabras claves: refugiados chilenos; seguridad nacional; Argentina.

\begin{abstract}
The overthrow of Salvador Allende, and the subsequent establishment of a military dictatorship in Chile, had wide repercussions in the complex Argentine political scene, which was overwhelmed by the arrival of the exiles. Although the government was not prepared for this situation, the agreement between the National Directorate of Migration (DNM), the United Nations High Commissioner for Refugees (UNHCR) and the Christian churches made it possible to create a national network that assisted thousands of Chileans. This article analyzes the changes in government perceptions and policies regarding the period of 1973-1983. It is argued that, in a complex process marked by ambiguities and contradictions that included both instances of integration and rejection, the progressive ascendancy of the national security perspective in the leadership of the successive governments motivated the Chileans under UNHCR protection to be gradually considered a threat, whose permanence in Argentina should be subject to regulation, control and, in specific cases, repression, physical elimination and / or expulsion. The state presence within the humanitarian network that protected them made the refugees more exposed, and their situation was more vulnerable than that of the exiles who had mixed with the migrant population. In contrast, when the Beagle conflict posed a new scenario in which Chileanness climbed positions in the order of threats, those protected by the UNHCR were the Chileans that were least affected by repressive action.
\end{abstract}

Keywords: Chilean refugees; national security; Argentina.

El derrocamiento de Salvador Allende, y la posterior instauración de una dictadura militar en Chile tuvieron amplias repercusiones en el complejo escenario político argentino que se vio desbordado por la llegada de los perseguidos políticos. Al igual que la mayoría de los países latinoamericanos, la Argentina no estaba preparada para esta situación; carecía no sólo de la infraestructura adecuada sino además de los procedimientos necesarios para estudiar y resolver los potenciales casos de refugiados $^{1}$. No obstante, el acuerdo entre la Dirección Nacional de

$1 \mathrm{La}$ problemática de los perseguidos políticos tenía antecedentes importantes en la historia política argentina del siglo XX. Los gobiernos neoconservadores (1932-1943) y peronistas (1946-1955) no consideraron a la población desplazada por la persecución política o racial como un problema en sí mismo 
Migraciones (DNM), el Alto Comisionado de las Naciones Unidas para los Refugiados (ACNUR) y las iglesias cristianas hizo posible la creación de una red nacional que asistió a miles de chilenos entre 1974 y 1989.

Los refugiados chilenos residentes en Argentina fueron soslayados por la historiografía durante mucho tiempo. Sin embargo, el progresivo avance de las investigaciones sobre el exilio y la represión en el campo de estudios sobre el pasado reciente argentino y la incorporación de nuevas preguntas y escalas de análisis hicieron visible esta problemática y revelaron su potencialidad como objeto de estudio. Algunas de las investigaciones priorizaron el análisis de los refugiados y/o exiliados, y los avatares de su integración en el país de acogida (PAREDES, 2007; GATICA, 2014; AZCONEGUI, 2014, 2016a). Estos estudios han mostrado, entre otras cosas, la pluralidad de la experiencia exiliar en Argentina - los refugiados, también con trayectorias diversas, constituyeron un reducido grupo dentro del universo más amplio de exiliados -, la especificidad de cada espacio geográfico y la compleja relación que los chilenos entablaron con las autoridades gubernamentales, el personal ligado al ACNUR y la sociedad en general. Paralelamente, las pesquisas han abordado la dimensión estatal resaltando el cambio de la política gubernamental, que pasó de la recepción a la expulsión, y la diversidad de los mecanismos represivos implementados (GONZÁLEZ, 2003; AZCONEGUI, 2014, 2016b, 2018; LASTRA y PEÑALOZA PALMA, 2016; CASOLA, 2017a, 2017b). En línea con estos trabajos, este artículo tiene como objetivo general contribuir a esclarecer la compleja trama político-institucional e ideológica que enmarcó la estancia de los chilenos en Argentina en el período 1973-1983. Dado que las opciones y condiciones de vida de los refugiados que permanecieron en el territorio estuvieron fuertemente condicionadas por los cambios en la política gubernamental, este trabajo reflexiona sobre algunas de las características que adquirió la Argentina como país de refugio en aquellos años. Por un lado, historiza el proceso de configuración de los refugiados chilenos como un "problema de seguridad nacional" que los convirtió en blancos potenciales de las fuerzas de seguridad y/o pasibles de ser deportados a su

para el Estado argentino y las consideraciones humanitarias sólo pesaron en los casos en que existió afinidad ideológica (JENSEN, 2004). 
país de origen ${ }^{2}$. Por el otro, examina el carácter de la presencia gubernamental en el programa humanitario y su impacto dentro de la política represiva del régimen militar y sus derivas en materia internacional.

El trabajo se basa en el análisis de la legislación en materia de migración, ciudadanía y seguridad nacional para reconstruir la manera en la cual quienes legislaban consideraron la presencia de los refugiados chilenos en la Argentina. Esta visión es complementada con referencias a la política efectivamente implementada teniendo en cuenta que no existió una relación lineal entre lo definido normativamente y las prácticas que efectivamente se desarrollaron, y que hubo una extendida presencia de prácticas ilegales durante el período ${ }^{3}$. Si bien el sujeto de estudio son los protegidos del ACNUR, se incorpora las percepciones sobre los colectivos más abarcadores de exiliados y extranjeros, en este caso chilenos, para establecer en qué medida existían similitudes y/o diferencias con respecto a las apreciaciones que de ellos hubo en los distintos momentos analizados.

\section{¿Víctimas de persecución o amenazas a la seguridad nacional?}

Producido el golpe de estado, la reacción del gobierno de Lastiri quien ejercía sus últimos días al frente del ejecutivo ante la inminente asunción de Perón - tuvo un carácter ambiguo y contradictorio que

\footnotetext{
2 La categoría exiliado es utilizada de manera genérica para hacer referencia a todas aquellas personas que abandonaron Chile a causa de las políticas represivas implementadas por el régimen militar. Refugiado se refiere a las personas reconocidas como tales en el marco del régimen global establecido por el ACNUR.

3 Como Alonso ha señalado, la llamada "legalidad del régimen" constituía de hecho una "pseudojuridicidad" - en el sentido de Aróstegui- que buscaba la legitimación de autoridades y de sus políticas públicas y encubría disposiciones que pretendían ajustarse a normativas y procedimientos legalmente establecidos de estricta justicia (ALONSO, 2015).
} 
contrastó con las declaraciones de franco repudio y solidaridad con el pueblo chileno de las cámaras del Congreso argentino ${ }^{4}$. Por ejemplo, la declaración de un duelo nacional de tres días por la muerte de Salvador Allende fue seguida del restablecimiento de las relaciones diplomáticas y el reconocimiento del gobierno de facto. De manera similar, la política de "puertas abiertas" para con los perseguidos políticos no se tradujo en una ayuda concreta o en el establecimiento de los mecanismos necesarios para concretarla. En consecuencia, algunas personas que utilizaron la vasta y porosa frontera para ingresar ilegalmente al país terminaron a disposición de gendarmería que los entregó a la policía chilena, desconociéndose hasta ahora su paradero (PEÑALOZA PALMA, 2016). Análoga fue la suerte de quienes buscaron amparo a través de la embajada en Santiago ya que el gobierno argentino fue en parte responsable de obstaculizar el arribo de los perseguidos al país. Mientras que en algunos casos no autorizó las entradas, en otros las demoró al realizar tareas de inteligencia e investigaciones que pasaron a engrosar los expedientes que los servicios de inteligencia de la Policía difundieron a las distintas fuerzas de seguridad en ese país y que sirvieron a la represión estatal en años posteriores (LASTRA y PEÑALOZA PALMA, 2016). En definitiva, como la declarada hospitalidad no fue acompañada de medidas políticas que la sustentaran, la misma entró en contradicción con las prácticas restrictivas y represivas de los agentes estatales quienes actuaron acorde a la legislación vigente heredera de la autodenominada Revolución Argentina - que apuntaba a "impedir la inmigración clandestina" y negaba la entrada al país a los extranjeros que por sus antecedentes fueran reputados comunistas ${ }^{5}$. Estas

\footnotetext{
4 Raúl Lastiri asumió como presidente interino el 13 de julio de 1973 debido a la renuncia del presidente Héctor Cámpora. En su mandato se celebraron las elecciones presidenciales en las que Juan Domingo Perón participó sin condicionamientos y ganó con el $62 \%$ de los votos asumiendo en octubre de ese año. Perón, por su parte, no dudó en capitalizar políticamente la crisis política chilena para tranquilizar a su propio frente interno. En su encuentro con los miembros de la Juventud Peronista caracterizó al gobierno de Allende como un ejemplo de la inconveniencia de "apresurar" los procesos revolucionarios y de la necesidad de encauzarlos de una forma gradual y pacífica (FRANCO, 2012).
}

5 Como DOMENECH (2011) argumenta, durante los años sesenta los inmigrantes limítrofes se convirtieron en los nuevos "indeseables" adquiriendo la ilegalidad una especial relevancia en la normativa producida. Paralelamente, la ley 17.401 establecía los mecanismos para identificar a las personas calificadas como comunistas y aplicar las sanciones correspondientes. En su articulado facultaba a la DNM, con intervención de la Secretaría de Informaciones de Estado, a fiscalizar el ingreso al país de las personas y aplicar la 
prácticas en las que subyace una criminalización de los perseguidos políticos constituyeron las primeras instancias en la configuración de exiliados chilenos (potenciales refugiados) como una amenaza.

Si bien la presidencia de Perón tuvo una respuesta más elaborada, la misma estuvo condicionada y atravesada por las tensiones y divisiones presentes en el movimiento y en el gobierno peronista. En consecuencia, su política con respecto al problema de los perseguidos políticos fue ambigua y con ciertas contradicciones, combinando medidas que favorecían su protección con otras que acercaban al líder argentino al régimen de Pinochet.

La integración de los chilenos se propició fundamentalmente desde la DNM. Mientras que un ínfimo número de personas recibió el asilo político ${ }^{6}$, otros pudieron permanecer en el país a través de dos mecanismos implementados de manera paralela: la amnistía de 1974, y la conformación de una red nacional de asistencia a refugiados.

Mientras trabajaba por el levantamiento de la reserva geográfica que haría posible que el gobierno argentino reconociera a los exiliados como refugiados, la DNM impulsó y formó parte activa y necesaria, junto con el ACNUR y las Iglesias cristianas, de la organización de un programa para que los exiliados chilenos se asentaran en el país y pudieran acogerse a la protección internacional de las Naciones Unidas en el territorio ${ }^{7}$. Paralelamente, generó las condiciones legales y fomentó la radicación de los perseguidos políticos como parte del grupo mayor de los inmigrantes

prohibición para aquellos que, por sus antecedentes, fueran reputados comunistas (B.O., 22 de agosto de 1967).

6 Durante 1974 recibieron asilo territorial sólo 4 personas de origen chileno (GONZÁLEZ, 2003).

7 Al firmar la Convención sobre el Estatuto de los Refugiados de 1951 el gobierno argentino decidió establecer la reserva geográfica por lo cual sólo se consideraron refugiados a las personas prevenientes de Europa. Si bien el protocolo de 1967 hizo extensivas las disposiciones de la Convención a nuevos grupos de refugiados al eliminar la fecha límite de 1951, en su adhesión la Argentina no modificó la reserva geográfica. En consecuencia, hasta que la Argentina no levantara la reserva geográfica, los refugiados residentes en el país serían protegidos por el ACNUR no por el Estado argentino.

Entre 1973 y 1975 el ACNUR reconoció un total de 11.299 refugiados. Paralelamente, el programa humanitario implementado en el marco del gobierno peronista asistió a 14.000 refugiados latinoamericanos que provenían de Chile y fueron reasentados en terceros países (AZCONEGUI, 2016b) 
que permanecían de manera ilegal en el país ${ }^{8}$. El carácter amplio del decreto de amnistía y las facilidades que el mismo otorgó para los recién llegados motivó el rechazo de quienes lo consideraron un instrumento para que los "guerrilleros subversivos" de los países limítrofes pudiesen entrar y legalizar su situación en el país (MÁRMORA, 1983) ${ }^{9}$. Las crecientes resistencias - incluso al interior del gobierno peronista - por la presencia de exiliados que conformaban en Argentina una "retaguardia revolucionaria", y la progresiva conflictividad sociopolítica local, condicionaron el diseño de las políticas hacia los exiliados así como también las actuaciones de quienes las llevaban adelante ${ }^{10}$. La preocupación por la seguridad de los chilenos llevó a los agentes migratorios a hacer una doble recomendación a los recién llegados: primero, que optaran por radicarse como migrantes en lugar de acceder al status de refugiados; y, segundo, que, si decidían obtener la protección del ACNUR, buscaran un tercer país ya que, por el momento, la Argentina no los reconocería como tales y su situación sería de extrema vulnerabilidad. Estas sugerencias - emanadas de la misma dirección que trabajaba por el levantamiento de la reserva geográfica y formaba parte activa y necesaria del programa humanitario que asistía a los refugiados en Argentina - reflejan el carácter crítico e incierto del contexto vivido. En resumen, si bien la DNM priorizó, por razones de seguridad, la integración de los chilenos como migrantes, también facilitó que los mismos accedieran a la protección del ACNUR, aunque dadas las conflictivas y cambiantes circunstancias que atravesaba el país se desconfiara de la viabilidad de esta opción.

8 Migrantes y refugiados -en total unas 24.449 chilenos- decidieron aprovechar las amplias facilidades que surgieron de la aplicación de la amnistía hasta mediados de 1974 (MÁRMORA, 1983).

9 Por ejemplo, informes de inteligencia de la Policía de Buenos Aires caracterizaba en noviembre de 1973 a los exiliados chilenos y a los residentes que se acogieron al asilo como subversivos, guerrilleros, y/o elementos relacionados con organizaciones subversivas" (LASTRA y PEÑALOZA PALMA, 2016).

10 Como señala MARCHESI (2012), las organizaciones armadas de izquierda, así como los militares conosureños, parecieron compartir la idea de que entre 1973 y 1976 en Argentina se desarrolló un conflicto central para el futuro del Cono Sur que trascendía la política nacional. En esos años el ERP facilitó el refugio a militantes de organizaciones de los países vecinos y proveyó los recursos materiales y humanos para planificar operaciones de retaguardia desde Argentina. 
En contraste, como el problema de los chilenos en la Argentina fue percibido no sólo desde una perspectiva poblacional (radicación en calidad de inmigrantes) y humanitaria (protección del ACNUR en carácter de refugiados) sino también geopolítica y de seguridad nacional, el gobierno peronista tuvo paralelamente un acercamiento al régimen militar de Pinochet. Esta perspectiva, presente en sectores gubernamentales cercanos a la Cancillería, quedó de manifiesto en decisiones que perjudicaron a los perseguidos políticos como la de frenar el proyecto del levantamiento de la reserva geográfica ${ }^{11}$, y trasladar a los diplomáticos que garantizaban el trabajo humanitario que se realizaba en la embajada argentina en Santiago (LASTRA y PEÑALOZA PALMA, 2016). Aunque estas actitudes generaron cierto rechazo en los argentinos, las mismas cumplieron los objetivos de evitar un posicionamiento claro de Perón (a favor o en contra) respecto a la "política antisubversiva" del régimen de Santiago; y de lograr un acercamiento a la dictadura trasandina que se cristalizó en el encuentro entre Perón y Pinochet de mayo de 1974, y en la firma de una declaración conjunta sobre los derechos soberanos de ambos países en el continente antártico.

La disputa entre estos distintos enfoques (el humanitario y poblacional frente al geopolítico y de seguridad nacional) sobre esta problemática fue en paralelo al proceso de descomposición del gobierno peronista. Las divisiones y tensiones internas que subyacían latentes bajo el liderazgo de Perón se dirimieron de manera más abierta y pública una vez fallecido el presidente. El proceso de "depuración ideológica" aplicado desde 1973 al partido y a los distintos niveles del gobierno (SERVETTO, 2010; FRANCO, 2012) alcanzó al referente gubernamental de Migraciones y del programa humanitario - quien debió partir al exilio -, generando el fin de una etapa.

A diferencia de la relación pragmática vinculada a consideraciones de equilibrio de poder subregional, que había primado bajo las gestiones de Lastiri y Perón; durante la gestión de Estela Martínez, el vínculo argentino-

11 Según Mármora, a cargo de migraciones en esos meses, el proyecto de revocar la reserva geográfica fue frenado en Cancillería y quedó desestimado al morir el presidente Perón (AZCONEGUI, 2016b). 
chileno se constituyó sobre la base de un paradigma de acercamiento ideológico entre los regímenes anticomunistas del Cono Sur ${ }^{12}$.

En medio de un clima de alta conflictividad y violencia, la política gubernamental se hizo cada vez más restrictiva y tomó fuerza la visión de los refugiados y exiliados políticos como una amenaza a la seguridad nacional. Este avance se plasmó en la legislación emanada del Congreso, aunque no sin cierta ambigüedad como lo reflejan las leyes de ciudadanía y seguridad nacional sancionadas en septiembre de 1974 con sólo un día de diferencia. Los cambios introducidos en la primera (ley 20.835), permiten incorporar matices y diferenciar a este período de los que lo precedieron y sucedieron. La nueva ley sólo modificó dos artículos: uno, para facilitar el procedimiento de rehabilitación del ejercicio de la ciudadanía; otro, para explicitar el impedimento de "negar (se) la ciudadanía por razones políticas, ideológicas, gremiales, religiosas o raciales"13. En estas innovaciones es posible identificar el intento de los congresistas de establecer diferencias dentro del amplio espectro de la militancia de izquierda permitiendo la obtención de ciudadanía a aquellos extranjeros que no incurrieran en la lucha armada en un contexto en el que se aceptaba implícitamente la existencia de la "subversión" y la necesidad de nuevas medidas penales para combatirla ${ }^{14}$. En una coyuntura de políticas cada vez más restrictivas - para los extranjeros pero también para los argentinos en general- las modificaciones en la ley de ciudadanía dejan traslucir la existencia de una perspectiva abierta a la pluralidad (puntualmente en este

12 El compromiso ideológico se evidenció en una serie de hechos que tuvieron importantes repercusiones como la prohibición de actos en solidaridad con el pueblo chileno, las visitas a Chile del ministro de Defensa Adolfo Savino - una figura ligada al lopezrreguismo - y del comandante en jefe del Ejército argentino, general Leandro Anaya un mes después del asesinato del general Prats, y la condecoración a Pinochet con la Gran Cruz de la Orden de Mayo al Mérito Militar. Por otra parte, la delegación argentina se opuso en dos oportunidades - 6/11/1974 y 9/12/1975 - a las resoluciones de las Naciones Unidas que condenaron al gobierno de Pinochet por "las constantes y flagrantes violaciones de los Derechos Humanos y libertades básicas" y urgieron a las autoridades de Santiago a "respetar en forma total los principios de la Declaración Universal de los Derechos Humanos" y a "adoptar todos los pasos necesarios para restaurar y salvaguardar los derechos humanos básicos y libertades funda-mentales" (CORIGLIANO, 2002).

13 Ley 20.835, sancionada el 27 de septiembre de 1974 (B.O., 13 de diciembre de 1974)

14 Considero que sería necesario analizar las discusiones parlamentarias para lograr una visión más comprensiva de los matices involucrados en el proceso. 
caso interesa la apertura político-ideológica) y superadora de aquella que negaba no sólo la ciudadanía sino también la entrada al país a los comunistas y que muy probablemente había sido el fundamento que había avalado la decisión, tomada en el gobierno de Lastiri, de retener en Ezeiza a quienes llegaban huyendo de Chile ${ }^{15}$. Más aún, el hecho de que la misma fuera posteriormente derogada por la dictadura bajo los argumentos de haber permitido "otorgar la ciudadanía a extranjeros con antecedentes desfavorables" es un dato que permite pensar que esta normativa (la ley de ciudadanía sancionada por el Congreso en el año 1974) pudo efectivamente haber funcionado como una opción más para los perseguidos políticos que pretendían permanecer en la Argentina ${ }^{16}$.

En contraste, el Congreso también aprobó la Ley de Seguridad (20.840) para "la represión de la actividad terrorista y subversiva", e incluyó castigos que establecían la expulsión de extranjeros y argentinos naturalizados ${ }^{17}$. Si bien la oposición cuestionó, entre otras cosas, la vaguedad y ambigüedad de los delitos que intentaba definir sin tipificar (FRANCO, 2012), la normativa fue sancionada sin resolver esas imprecisiones. A diferencia de la Ley de Ciudadanía que brindaba intersticios legales que podían ser aprovechados por los perseguidos políticos en su búsqueda por sobrevivir en un país cada vez más peligroso, la Ley de Seguridad cerraba caminos al aumentar la capacidad represiva del Estado sobre los extranjeros. Más aun, la manera en que esta ley fue implementaba transformó al conjunto de los refugiados en un problema de seguridad. En consecuencia, la represión legal fue direccionada hacia ellos y los refugios en los que vivían y, de manera colateral, recayó sobre los nodos que articulaban la red nacional que los asistía. Paralelamente, y en sintonía con el avance de la represión paraestatal e ilegal en el país, los refugiados, el personal y las sedes fueron sujeto de las acciones de la Triple

15 Me refiero a la mencionada ley 17.401 en vigencia desde 1967 (B.O., 22 de agosto de 1967).

16 La ley de ciudadanía 20.835 fue derogada en 1977 por el régimen dictatorial.

17 Ley 20.840, sancionada el 28 de septiembre de 1974 (B.O., 2 de octubre de 1974). La existencia de leyes que estipulaban la expulsión de extranjeros considerados "indeseables" tenía una historia en nuestro país que se remontaba a la deroga Ley de Residencia de 1902 pero más recientemente a la dictada en el régimen de Onganía inmediatamente después del Cordobazo (DOMENECH, 2011). 
A y de la coordinación represiva regional ${ }^{18}$. Finalmente, luego de una serie de disposiciones restrictivas el gobierno peronista definió la no aceptación de los refugiados y su relocalización en terceros países (AZCONEGUI, 2014). Esta decisión que se sumó al avance represivo antes mencionado fue devastadora para la "entente humanitaria" ya que la red nacional de asistencia a los refugiados encontraba cada vez mayores dificultades para seguir funcionando sin la colaboración y, mucho menos, con la oposición de uno de sus pilares: el Estado. La incertidumbre inicial con respecto a la responsabilidad gubernamental en la avanzada represiva se despejó con el golpe del 24 de marzo de 1976.

\section{Los chilenos como una doble amenaza}

El primer paso de la dictadura de 1976 en relación a la situación de los refugiados fue determinar la posición que iba a adoptar. Con este fin el ministerio del Interior resolvió la conformación de una comisión ad hoc para analizar las distintas aristas involucradas en el problema. La misma composición del flamante organismo, integrado por personal de Cancillería, de la Secretaría de Inteligencia del Estado (SIDE) y de los servicios de seguridad, brinda indicios sobre la perspectiva que el régimen privilegiaba. En particular, llama la atención la ausencia de referentes de la DNM (o de áreas afines) que había sido la entidad gubernamental encargada de organizar el programa humanitario en curso y de propiciar la radicación de miles de perseguidos políticos en 1974. Esta omisión evidencia el abandono de la perspectiva poblacional y la primacía del enfoque geopolítico y de seguridad nacional en donde la lógica humanitaria tenía, en el mejor de los casos, sólo un lugar funcional. En línea con el perfil de su constitución, la Comisión sugirió, por un lado, una política restrictiva que insistió en la no aceptación de las llamadas "personas indeseables", y, por el otro, insistió en la necesidad de un tratamiento cuidadoso del

18 Sobre la represión de los refugiados y el programa humanitario consultar PAREDES (2007), AZCONEGUI (2014), PEÑALOZA PALMA (2016), CASOLA (2017a). 
"problema de los refugiados" hasta que fueran relocalizados para evitar así las condenadas internacionales. En definitiva, luego del análisis y la deliberación, la dictadura implementó para el "problema de los refugiados" una respuesta que combinó una política de carácter represivo y expulsivo en el plano interno con una resignificación y manipulación de su perturbadora permanencia en el país para forjar una imagen positiva de la dictadura como un régimen moderado, respetuoso de los derechos y humanitario (AZCONEGUI, 2018).

Aunque los exiliados y refugiados constituyeron un enemigo periférico (CASOLA, 2017a), ellos fueron sujeto de políticas específicas de vigilancia, regulación y control ${ }^{19}$. La aplicación de los decretos 1483/76, 2699/76 y 1966/77 le permitió al gobierno dictatorial conformar una suerte de "padrón de extranjeros bajo protección del ACNUR". A través de ellos las autoridades pretendían obtener los antecedentes, el lugar de residencia y la cantidad de personas refugiadas que residían ilegalmente en Argentina y "no podían volver a su país de origen por razones políticas, raciales y/o religiosas". Sin embargo, la política fue resistida y los datos obtenidos fueron parciales $^{20}$. Justificada como parte de una política poblacional eficiente, la sensible información recabada por el Estado tuvo, sin duda, un importante valor para las fuerzas de seguridad que en ese momento integraban la coordinación represiva regional (SERRA PADRÓS y SLATMAN, 2012). Además de esta medida, las fuerzas de seguridad contaron con al menos dos mecanismos más que les permitían vigilar a este grupo de personas a priori sospechosas. El primero de ellos era la presencia policial en las sedes cristianas que trabajaban para el ACNUR en distintos puntos del país. Entre requerida e impuesta, esta figura facilitó las tareas de

19 Sobre las características que adquirió la regulación, control y represión de la población durante la dictadura, así como los cambios y continuidades en materia represiva en el período 1973-1983 ver la obra colectiva coordinada por ÁGUILA (2016).

20 Según documentación de la DNM, en cumplimiento de estos decretos se registraron 1932 extranjeros que se declararon como "refugiados" entre años 1976 y 1977 (DNM, 1983). Esta cifra es considerablemente menor a los datos de las agencias que trabajaban en el programa humanitario que registraban la presencia de 10.000 refugiados en septiembre de 1977, un mes después de finalizado el empadronamiento (CCAS, 1977). El sub-registro de las autoridades evidencia la decisión de los perseguidos políticos en situación de ilegalidad de no comparecer ante las autoridades. Esta actitud puede ser interpretada como una más de las estrategias desarrolladas por los refugiados para sobrevivir durante los años de la dictadura. 
inteligencia sobre las actividades humanitarias, su personal y los mismos refugiados. Es decir, las agencias devinieron colaboradores involuntarios en la detección de futuros blancos represivos (AZCONEGUI, 2014, 2018). En segundo lugar, y en clara sincronía, los archivos de la Dirección de Inteligencia de la Policía de Buenos Aires (DIPBA) reflejan que el status de refugiado funcionó como una autoincriminación a partir de la cual se iniciaron legajos para poder establecer en qué medida esa persona o grupo de personas contribuían a los objetivos y las energías de la izquierda local (CASOLA, 2017b). Utilizadas de manera aislada o combinada, estas vías de regulación y control constituyeron fuentes de útil información para allanamientos y detenciones como los realizados en las sedes y refugios en Buenos Aires, Neuquén y Mendoza en 1975 bajo el gobierno peronista y desde 1976, aún antes de que el gobierno militar fijara su política en materia de refugiados.

En línea con lo planteado, el status de refugiado y la protección que aportaba el programa devino un "arma de doble filo" para los miles de chilenos que vivieron su exilio en aquellos años en la Argentina. Al igual de lo que sucediera con la sociedad en general, la política represiva sobre ellos continuó e, incluso, aumentó después del golpe. Entonces, mientras permanecieron en la Argentina el régimen militar hizo más que tolerar la presencia de los refugiados y el accionar de las agencias involucradas en su protección, utilizó su lugar en el programa para controlar su funcionamiento, vigilar y amedrentar a las personas implicadas, allanar oficinas y refugios, y utilizar la información recabada en los operativos para concretar otros objetivos represivos propios y/o de sus asociados en el marco de la coordinación represiva regional ${ }^{21}$.

Paralelamente, la sospecha sobre la peligrosidad y amenaza no se circunscribió al grupo de los refugiados, sino que abarcó al colectivo de los extranjeros. Esta desconfianza se evidenció en las modificaciones introducidas en las normativas que afectaban la entrada, permanencia y salida de las personas del país. Estos cambios, pensados para regular a toda la población extranjera, incluía dentro de los sujetos afectados a los

21 Algunos de estos casos fueron considerados por el Tribunal Oral en lo Criminal Federal $\mathrm{N}^{\circ} 1$ de Buenos Aires en la causa "Plan Cóndor". En el marco de este juicio fueron condenados quince militares en mayo de 2016. 
refugiados que quisieran regularizar su situación así como también a los exiliados políticos que residían en el país como migrantes en distintas situaciones de legalidad ${ }^{22}$.

La ley se Seguridad Nacional del 24 de marzo de 1976 identificaba la clara oposición entre "la acción disociadora o criminal de algunos extranjeros que, burlándose de la tradicional generosidad argentina, atentaba de diversa manera contra el pueblo y las instituciones del país que le brindaban hospitalidad" y los objetivos prioritarios e irrenunciables de la "paz social" y la "seguridad nacional" fijados por el "Gobierno Nacional" "23. Y, en consecuencia, habilitaba al Poder Ejecutivo a ordenar la expulsión de extranjeros (con residencia permanente o no permanente) con condenas en el exterior y/o en la Argentina, pero también la de aquellos que realizaran "actividades que afecten la paz social, la seguridad nacional o el orden público”. En línea con su predecesor, la dictadura incluyó a los extranjeros dentro del amplio abanico de fuerzas sociales y políticas demonizadas por sus ideas y acciones, e identificadas bajo el rótulo de "enemigos de la Nación"24.

De manera similar, con la necesidad de dotar al Estado con más instrumentos para "asegurar la vigencia de la seguridad nacional, erradicando la subversión y las causas que favorecen su existencia" la dictadura fundamentó las restricciones en la Ley de Ciudadanía ${ }^{25}$. En ella se argumentó que como la naturalización implicaba la incorporación de los extranjeros al cuerpo político de la Nación el Estado debía "extremar sus recaudos para evitar que se infiltren en su seno elementos indeseables cuya conducta pueda atentar contra los principios fundamentales sobre los cuales

22 Si bien la política general de la dictadura fue la no aceptación y expulsión de los refugiados, a partir del "empadronamiento" antes mencionado la dictadura dictaminó quiénes podían radicarse y quienes debían partir, resultando estos últimos ampliamente mayoritarios. Sobre las diferentes opciones legales de los chilenos ver AZCONEGUI (2014).

23 Ley 21.259 (B.O., 26 de marzo de 1976). Es importante destacar que estas normas fueron sancionadas por la Comisión Asesora Legislativa $(\mathrm{CAL})$ creada por el gobierno dictatorial y conformada por nueve miembros (tres de cada Fuerza).

24 Para profundizar sobre esta construcción en el período 1973-1976 ver FRANCO (2012).

25 Ley 21.610 sancionada 26 de julio de 1977 (B.O., 5 de agosto de 1977). 
descansa su organización". Entonces, para adecuar la normativa al paradigma de la Seguridad Nacional, realizó una doble modificación en materia de ciudadanía. Primero, derogó la ley del gobierno de Estela Martínez (20.835) por considerar que la misma había permitido "otorgar la ciudadanía a extranjeros que registraban antecedentes desfavorables" y que era "inconveniente" mantener un artículo que imposibilitaba "negar (se) la ciudadanía por razones políticas, ideológicas, gremiales, religiosas o raciales". Segundo, introdujo innovaciones agregando artículos que afectaban su otorgamiento y cancelación. Como se videncia en el articulado, el sesgo político-ideológico de la nueva legislación era claro ya que explicitaba como causales que impedían la obtención de la ciudadanía condiciones como "profesar doctrinas que combatan la forma de gobierno de la República y hacer pública exteriorización de las mismas" y "haber desarrollado actividades que comprometan la seguridad nacional, la paz social o el orden público". No obstante, estos condicionamientos convivían en la ley con otros que se alejaban de dicho paradigma. Por ejemplo, resultaba un impedimento para ser ciudadano argentino "ser o haber sido ciudadano o súbdito de un país que se encuentre en guerra contra la Nación Argentina" y, al mismo tiempo, eran causales de cancelación de la ciudadanía por naturalización, tanto las posturas y acciones políticoideológicas arriba mencionadas como la traición a la Patria. Es decir, la normativa provee indicios para pensar que quienes legislaban en el marco de la dictadura estaban influenciados por el paradigma de la seguridad nacional pero también por las ideas del nacionalismo territorial cuyo protagonismo en los círculos militares y en la esfera pública fue creciendo en el marco del conflicto limítrofe con Chile (LACOSTE, 2003). En suma, la ambigüedad de los enunciados que restringieron el acceso a la ciudadanía al colectivo de los migrantes políticos (y con ello condicionaron sus estrategias de integración) evidencia que la caracterización de los extranjeros residentes en la Argentina, en este caso los chilenos, como potenciales enemigos de la seguridad nacional se configuró como una dimensión más del proceso de identificación del "enemigo interno" que operó en paralelo a la participación en la coordinación represiva regional ${ }^{26}$.

26 Si bien la legislación habla de los extranjeros en general y no de los chilenos, la coyuntura política que enmarca estas normativas, la crítica a las políticas del peronismo que había privilegiado la integración de los chilenos y el hecho de que Argentina haya sido el principal destino del exilio chileno (se estima que recibió 
No obstante la validez de esta caracterización para interpretar la visión que de los exiliados y refugiados chilenos tenían quienes legislaban y gobernaban durante la dictadura, el conflicto del Beagle planteó un nuevo escenario $^{27}$. Si hasta ese momento el objeto de protección más importante era "el mundo occidental y cristiano" amenazado por la "subversión" en el marco de la guerra fría, a partir de 1977 hubo un cambio. El laudo arbitral contrario a la postura argentina sobre el diferendo en la zona del Canal de Beagle reactivó una histórica hipótesis de conflicto de carácter limítrofe entre Estados Nacionales que enfrentó a dos aliados ideológicos, Argentina y Chile, siendo la integridad de la nación y del territorio el valor más preciado a defender. A pesar de que en el marco de la coordinación represiva regional hubo una comunidad de intereses económicos e identidades políticas y una coincidencia en la comprensión estratégica del primado de las "fronteras ideológicas", que subordinaba, incluso, el efecto funcional de las fronteras políticas, este proceso no estuvo exento de contradicciones como lo evidencia éste entre otros conflictos (PADRÓS y SLATMAN, 2012). La progresiva escalada bélica generó una modificación en el lugar asignado a las "minorías chilenas" en el esfuerzo de inteligencia en base a la "posición potencialmente peligrosa" que asumirían en caso de desatarse un conflicto bélico con el país vecino (MONTERO, 2018). Si consideramos que a partir de 1978 se verificó un relajamiento de las tendencias represivas en la región (PADRÓS y SLATMAN, 2012) y que la "chilenidad" cobró fuerza como factor de amenaza es posible plantear que la coyuntura del Beagle operó de manera tal que alteró el orden de prelación de las amenazas elevando al enemigo territorial sobre el ideológico y que, en consecuencia, quienes habían sido considerados como

al $50 \%$ de las personas que huyeron de Chile) permiten pensar a estas medidas como parte de un intento de contrarrestar las estrategias de camuflaje de muchos de los exiliados quienes habían optado por no sacar el status de refugiados y mimetizarse dentro de la numerosa migración chilena. Sobre las estrategias de los exiliados chilenos ver PAREDES (2007), GATICA (2014), AZCONEGUI (2014)

27 Aunque el inicio de los diferendos limítrofes con Chile se remonta a fines del siglo XIX, en 1971 el presidente de facto Agustín Lanusse recurrió a un tribunal arbitral para el caso Beagle. El fallo adverso a la posición argentina se dio a conocer en mayo de 1977. A partir de allí y hasta diciembre de 1978, las relaciones entre ambos países se deterioraron vertiginosamente y se inició un proceso de tensiones militares en la frontera trasandina. La mediación papal, a través del cardenal Samoré, logró detener el conflicto que se consideraba inminente. La resolución final llegó en el gobierno de Raúl Alfonsín. Los ministros de relaciones exteriores de ambos países firmaron el "Tratado de Paz y Amistad" en 1984. Una consulta popular realizada en Argentina en noviembre de ese año avaló el acuerdo. 
aliados devinieron enemigos sujetos de seguimiento, investigación y detención ${ }^{28}$.

Las derivaciones de este cambio en la percepción de las amenazas no se circunscribieron a la población chilena. También recayeron sobre argentinos vinculados al programa humanitario ( $\mathrm{y}$, en consecuencia, a la asistencia de refugiados chilenos) ya que, en provincias de frontera, como Neuquén, hubo detenidos en el marco de la Ley de Seguridad Nacional bajo acusaciones de "traición a la patria". Las buenas relaciones que mantenía la oficina del ACNUR con las autoridades gubernamentales en esta ciudad se alteraron en 1978 cuando el referente local fue detenido. A diferencia de sus pares en otras ciudades que, como ya mencionamos, sí habían sido afectados directamente por la política represiva del Estado al igual que los refugiados que protegían, el agente neuquino no había sido sujeto de represión, aun cuando hubo refugiados detenidos y desaparecidos en su zona de influencia y a pesar de que contaba con una doble pertenencia que lo hacía pasible de ser perseguido por las fuerzas de seguridad $^{29}$. Su repentina transformación en sospechoso y sujeto de detención en el marco del conflicto del Beagle refuerza la hipótesis de que la escalada bélica alteró el peso de los distintos elementos que configuraban la categoría de enemigo. En esa coyuntura se habrían incorporado como "subversivos" (susceptibles de ser detenidos en aplicación de la ley 20.840) nuevos comportamientos y personas ${ }^{30}$.

$28 \mathrm{Si}$ bien esta hipótesis necesita mayor investigación para ser corroborada, es muy sugerente el caso de Enrique Arancibia Clavel quien constituía una pieza clave de la Operación Cóndor, en su calidad de enlace entre la DINA y los servicios argentinos, y en noviembre de 1978 fue detenido en el marco de una causa por espionaje contra el Estado argentino.

29 Con doble pertenencia quiero hacer referencia a que, por un lado, era el encargado de un programa que protegía a refugiados políticos; y, por el otro, era un laico que ocupaba ese puesto por ser amigo personal del titular de la Iglesia Católica neuquina, Jaime de Nevares, a quién las fuerzas de seguridad y los católicos aliados al gobierno de facto llamaban "obispo rojo". Cabe aclarar que, en contraste a lo sucedido con este agente humanitario, los sacerdotes y laicos católicos que comulgaban con las ideas y las prácticas del catolicismo liberacionista sí fueron objeto de una vigilancia y persecución constante. En reiteradas oportunidades durante el período 1973-1983 el obispo Jaime de Nevares escribió a las autoridades militares de la región para quejarse de la vigilancia, persecución, atropellos y difamación de que eran objeto los miembros de la comunidad católica neuquina (obispo, sacerdotes y laicos).

30 La acusación de "traición a la patria" no fue exclusiva de esta coyuntura. La dictadura caracterizó a los opositores como "enemigos", los estigmatizó como anti argentinos y, en algunos casos, los criminalizó bajo 
En la medida en que cobró fuerza dentro del gobierno militar y algunos sectores de la sociedad la imagen de Chile como un país expansionista y sustractor de territorio y, en contrapartida, la visión de la Argentina como una nación en retroceso (LACOSTE, 2003), fue creciendo la animadversión hacia la población chilena en general ${ }^{31}$. La inminencia del enfrentamiento armado fue vivida con profundo temor principalmente por los chilenos que residían en la Patagonia, a cuyos oídos había llegado el rumor de que serían internados en "campos de concentración" en sitios estratégicos de Argentina para que operasen como escudo humano. Esta amenaza que se materializaba según fuera el caso en el traslado a la represa del Chocón (Neuquén), a la destilería de YPF en Luján de Cuyo (Mendoza) o al dique Florentino Ameghino (Chubut), tenía su correlato en la cotidianeidad ya que fueron testigos de la preparación para la guerra (constantes movimientos de camiones con pertrechos militares, desplazamiento de tropas, traslado de ataúdes y ocupación de escuelas) y padecieron en diversas formas la avanzada represiva del Estado (PAREDES, 2007; BAEZA, 2007; GATICA, 2014; AZCONEGUI, 2016a). Las experiencias de los chilenos en este contexto fueron muy diversas. No obstante, las investigaciones dan cuenta de la incertidumbre y la imposibilidad de decodificar los criterios utilizados por las fuerzas argentinas que en definitiva detenían en función de la chilenidad sin importar la situación legal de la persona (nacionalizada, residente o indocumentada). Si bien la dictadura recurrió al miedo y a la arbitrariedad para controlar a los chilenos, los estudios realizados en Patagonia evidencian que aun en esas circunstancias hubo intersticios de solidaridad argentino-chilena que permitieron contrarrestar, en cierta medida, los

acusaciones diversas como las de "subversivos" o "traidores". Por ejemplo, estas imputaciones recayeron sobre algunos actores del entramado humanitario y los exiliados que denunciaban las violaciones a los derechos humanos realizadas por el régimen militar.

No obstante, lo que quiero destacar es que la detención del agente humanitario no fue motivada en un cambio de su comportamiento sino en las modificaciones introducidas en las lentes con las que las fuerzas de seguridad lo observaban y vigilaban desde 1974.

31 Los militares contribuyeron a profundizar la idea del "enemigo chileno" y utilizaron a las escuelas como vehículo para lograr adhesiones (RODRÍGUEZ, 2010). 
efectos de la política estatal, siendo la intermediación del ACNUR un elemento importante en el caso de los refugiados (PAREDES, 2007; GATICA, 2014; AZCONEGUI, 2016a) ${ }^{32}$. En suma, cuando la chilenidad escaló posiciones en el orden de las amenazas y la "expulsabilidad"33 (la posibilidad de ser removido del espacio territorial del Estado-nación) operó como un mecanismo que mantuvo a los chilenos residentes en un estado de permanente provisoriedad, los protegidos de Naciones Unidas (máximos destinatarios de la vigilancia y la represión durante el período), resultaron el colectivo menos vulnerable.

La fragilidad de la permanencia de los chilenos en Argentina durante la dictadura reapareció en el contexto de la Guerra de Malvinas entre abril y junio de 1982. La ayuda de Chile a Gran Bretaña ${ }^{34}$ reavivó las tensiones entre los regímenes militares conosureños y, en consecuencia, la Argentina mantuvo tropas entrenadas asegurando su frontera oeste durante el conflicto (ROMERO citado en PAREDES, 2007). Paralelamente, un significativo sentimiento anti chileno se apoderó nuevamente de la sociedad civil y los trasandinos que residían en el país sufrieron las consecuencias (PAREDES, 2007; GATICA, 2014). A la hora de responder al nuevo escenario de aprestos bélicos, numerosos patagónicos se apoyaron en la capa de memorias constituida por los sucesos similares que ya habían vivido en el año 1978 (LORENZ, 2011). Así, los chilenos devinieron sospechosos y peligrosos, potenciales espías y traidores. Aunque en ciudades como Comodoro Rivadavia esta situación generó en algunas

32 Ante la creciente animadversión general en contra de los chilenos, desde el programa humanitario se trabajó de manera coordinada con el encargado de la DNM, coronel Remigio Azcona, para proteger a los refugiados siendo algunos de ellos relocalizados.

33 La expulsabilidad está implicada en normas y prácticas administrativas específicas destinadas a la población migrante. Como DOMENECH (2017) argumenta, aunque un alto porcentaje de órdenes de expulsión nunca son ni serán ejecutadas, la mera existencia de la figura de la expulsión tiene efectos concretos sobre la vida cotidiana de los inmigrantes.

34 La ayuda del gobierno chileno a las fuerzas británicas consistió en la provisión de datos de inteligencia sobre las actividades de la aviación argentina, el permiso para que naves de reconocimiento británicas utilizaran bases aéreas chilenas, y el desplazamiento de unidades militares a la frontera con Argentina, para "aferrar" regimientos de élite argentinos a la cordillera de los Andes. Como contrapartida, el Estado chileno recibió misiles, aviones a bajo costo y algunas unidades navales (LORENZ, 2011). 
organizaciones la necesidad de expresar públicamente las diferencias con las políticas del Estado chileno y mostrar el apoyo a los reclamos de soberanía argentina sobre las Islas Malvinas (BAEZA, 2007; TORRES, 2008), no hubo reacciones en el programa humanitario. Según la documentación relevada, a diferencia del año 1978 la nueva escalada bélica no generó contactos con el personal de la DNM ni relocalización de refugiados. La ausencia de planes de contingencia en el marco de la "entente humanitaria" y su red de agencias en distintos lugares del territorio, así como la inexistencia de víctimas en sus registros permiten argumentar que la coyuntura de 1982 resultó menos crítica para la seguridad de los refugiados.

Finalmente, la sanción de una nueva ley de migracione ${ }^{35}$ fue no sólo la respuesta más elaborada sino también la de más largo alcance rigió hasta el 2004 -, que aportó la dictadura militar en la regulación de la entrada, permanencia y salida de personas en el territorio. Esta ley, que abordaba el asunto migratorio bajo la óptica de la soberanía y la seguridad nacional, reafirmó conceptos como la idea de presentar al inmigrante como un peligro para el orden público; instaló nuevas prácticas autoritarias al facultar a la DNM y a su policía auxiliar a ordenar y ejecutar detenciones y expulsiones de extranjeros sin ningún tipo de intervención o control del Poder Judicial; e indujo a los miembros de la sociedad a involucrarse en actitudes de delación al establecer la obligatoriedad de denunciar la existencia de personas extranjeras sin documentación (NOVICK, 1992). No obstante, ni siquiera en dictadura se cumplieron todas sus prescripciones. La pervivencia del programa humanitario y su capacidad para seguir asistiendo a los refugiados en continuo contacto con personal de la DNM reflejan que la normativa no pudo evitar que la trama de relaciones personales preexistentes, ya sea intra o extrainstitucionales, siguieran teniendo un significativo rol en los procedimientos burocráticos que se realizaban (AZCONEGUI, 2014). Asimismo, la permanencia de miles de chilenos como ilegales es un dato importante porque demuestra tanto la colaboración de los vecinos y de los empleados de las reparticiones estatales que decidieron no denunciarlos como la distancia existente entre

35 La "Ley general de migraciones y fomento de la inmigración" (ley 22.439) conocida como "ley Videla" fue sancionada y promulgada el 23 de marzo de 1981 (B.O., 27 de marzo de 1981). 
el ideario presente en la cúpula gubernamental y distintos sectores de la sociedad, aún en los empleados públicos.

\section{Reflexiones finales}

El recorrido cronológico evidencia un progresivo crecimiento de la perspectiva de la seguridad nacional en función de la cual los refugiados, pero también el colectivo más amplio de los exiliados ingresados al país a partir del 11 de septiembre de 1973, constituyeron una amenaza al mundo occidental y cristiano. Aunque desde el gobierno constitucional de Lastiri hubo medidas enmarcadas en esta doctrina, su aplicación en la administración de los refugiados que residían en Argentina fue un proceso marcado por ambigüedades y contradicciones.

La respuesta elaborada durante el gobierno peronista para resolver la situación de los refugiados estuvo condicionada y atravesada por las tensiones y divisiones presentes en el movimiento y en el régimen. $\mathrm{La}$ ausencia de un consenso extendido sobre el rumbo a seguir hizo posible que quienes veían en los "recién llegados" a perseguidos políticos pudieran implementar, desde la DNM, medidas que permitieron que miles de chilenos encontraran resguardo en la Argentina en calidad de refugiados o migrantes. Esta oficina gubernamental no fue la única en trabajar en esa dirección. En una coyuntura de políticas cada vez más restrictivas - para los extranjeros, pero también para los argentinos en general - los legisladores decidieron eliminar los condicionamientos (políticoideológicos, entre otros) en el otorgamiento de la ciudadanía generando así una opción más para que los extranjeros (los chilenos) no vinculados a la lucha armada pudieran regularizar su situación. No obstante, estas iniciativas coexistieron en permanente tensión con el avance del discurso y la política que en nombre de la seguridad nacional perseguía y reprimía principalmente a los refugiados (en parte gracias a la información privilegiada que el Estado tenía por ser partícipe imprescindible del programa humanitario).

El golpe de estado y la instauración de la dictadura trajeron aparejada la cristalización del tema de los exiliados y refugiados políticos 
como un "problema de seguridad nacional". El relevamiento legislativo evidencia el avance en la regulación y control de los refugiados y de los extranjeros (en paralelo al de la población nativa) y cómo quienes legislaban fueron adecuando la normativa al marco interpretativo imperante; estableciendo incluso una nueva ley de migraciones. En ese contexto, los refugiados estuvieron muy expuestos al accionar represivo y su situación fue de mayor vulnerabilidad que la de los exiliados políticos que se habían mezclado con la población migrante.

No obstante la validez de esta caracterización para interpretar la visión que de los exiliados y refugiados chilenos tenían quienes legislaban y gobernaban durante la dictadura, el conflicto del Beagle planteó un nuevo escenario en el que el valor a defender pasó a ser la integridad de la nación y del territorio. Cuando la chilenidad escaló posiciones en el orden de las amenazas, y la "expulsabilidad" (la posibilidad de ser removido del espacio territorial del Estado-nación) operó como un mecanismo que mantuvo a los residentes en un estado de permanente provisoriedad, los protegidos de Naciones Unidas (máximos destinatarios de la vigilancia y la represión durante el período), resultaron el colectivo menos vulnerable.

$\mathrm{Si}$ el análisis normativo refleja un progresivo crecimiento de la perspectiva de la seguridad nacional, la confrontación con la política realmente implementada evidencia no sólo la distancia existente entre la prescripción y la aplicación de la norma sino también el entramado social que subyacía a la administración de la permanencia de los perseguidos políticos en el país. El efectivo funcionamiento del programa humanitario y su capacidad de asistir a los refugiados más allá de los cambios a nivel institucional (el derrocamiento del gobierno constitucional y su reemplazo por una dictadura) y de políticas gubernamentales (el paso de la protección a la expulsión) demuestra el peso de las relaciones interpersonales y de las tramas interinstitucionales en la materialización de la ayuda concreta a los chilenos amparados por el ACNUR. Finalmente, las acciones de solidaridad argentino-chilenas en el marco del conflicto limítrofe con Chile generan nuevos interrogantes para problematizar las actitudes y comportamientos de la sociedad civil frente a las políticas de la última dictadura militar en Argentina. 


\section{Bibliografía}

ÁGUILA, Gabriela et. al. Represión estatal y violencia paraestatal en la historia reciente argentina Nuevos abordajes a 40 años del golpe de Estado. La Plata: UNLP, 2016.

ALONSO, Luciano. ¿Qué era lo normal? Represión y pseudo-juridicidad en la última dictadura militar argentina”. Revista Contenciosa, Año III, n 5, 2015.

AZCONEGUI, M. Cecilia. Chilenos en Argentina, entre la protección del Alto Comisionado de las Naciones Unidas para los Refugiados (ACNUR) y la política de expulsión de la dictadura militar. En: JENSEN, Silvina y LASTRA, Soledad (comp.). Exilio, represión y militancia. Nuevas fuentes y nuevas formas de abordaje de los destierros de la Argentina de los setenta. La Plata; UNLP, 2014, pp. 215250.

AZCONEGUI, M. Cecilia. El gobierno peronista frente al exilio chileno. La experiencia de la red nacional de asistencia a los refugiados (1973-1976), Revista Izquierdas, $\mathrm{N}^{\circ} 26,1-25$, (2016b).

AZCONEGUI, M. Cecilia. Iglesia, Estado y sociedad. La protección de los refugiados chilenos en la Norpatagonia, 1973-1983, Revista de Historia de la Universidad Nacional del Comahue, UNCo, Neuquén, № 17, 145-174, 2016 a.

AZCONEGUI, M. Cecilia. La dictadura militar argentina y los usos del programa humanitario de protección a refugiados. En: LASTRA, Soledad (comp.). Exilios: un campo de estudios en expansión. Buenos Aires, CLACSO, 2018, pp. 19-40.

BAEZA, Brígida. Cruzar la frontera en los '70. Chilenos en Comodoro Rivadavia. En: BAEZA, Brígida et. al (comp.). Comodoro Rivadavia a través del siglo XX. Nuevas miradas, nuevos actores, nuevas problemáticas. Buenos Aires, Talleres de Gráfica MPS S.R.L. Buenos Aires, 2007, pp. 391 a 423.

CASOLA, Natalia. La represión estatal hacia los exiliados chilenos entre 1973 y 1983. ESTUDIOS, N 38, 2017a, pp. 69-86.

CASOLA, Natalia. Los indeseables. El exilio chileno en la mirada de la DIPBA (1973-1983). Clepsidra. Revista Interdisciplinaria de Estudios sobre Memoria. Vol. 4, N 7, 2017b, pp. 50-67.

CORIGLIANO, Francisco. Las relaciones entre Argentina y Chile 1973-1976: El doble canal de vinculación. POSTData Revista de Reflexión y análisis político, $\mathrm{N}^{\circ}$ 8, 2002, pp. 159-195. 
DOMENECH, Eduardo. Crónica de una 'amenaza' anunciada. Inmigración e 'ilegalidad': visiones de Estado en la Argentina contemporánea". En: BELA FELDMAN-BIANCO, Liliana et. al. (comp.). La construcción social del sujeto migrante en América Latina: prácticas, representaciones y categorías. Quito: CLACSO, 2011, pp. 31-72.

DOMENECH, Eduardo. Las políticas de migración en Sudamérica: elementos para el análisis crítico del control migratorio y fronterizo. Revista Crítica de Sociología e Política, Vol. 8, N 1, 2017, pp. 19-48.

FRANCO, Marina. Un enemigo para la Nación. Orden interno, violencia y "subversión", 1973-1976. Buenos Aires: FCE, 2012.

GATICA, Mónica. ¿Exilio, migración, destierro? Trabajadores chilenos en el Noreste de Chubut (1973-2010). Buenos Aires: Prometeo, 2014.

GONZÁLEZ, María. Los refugiados del Cono Sur durante regímenes autoritarios”. Tesis de Maestría en Políticas de Migraciones Internacionales. FSOC, UBA, 2003.

JENSEN, Silvina. Suspendidos de la Historia - Exiliados de la Memoria El caso de los argentinos desterrados en Cataluña (1976 -...). Tesis Doctoral. Departament d'Història Moderna i Contemporània. Facultat de Filosofia i Lletres. Universitat Autònoma de Barcelona, 2004.

LACOSTE, Pablo. La imagen del otro en las relaciones de la Argentina y Chile (1534-2000). Buenos Aires: FCE, 2003.

LASTRA, Soledad y PEÑALOZA PALMA, Carla. Asilos en dictaduras: chilenos en la embajada argentina. Perfiles Latinoamericanos. Vol. 24, $\mathrm{N}^{\circ} 48,2016$, pp. 83109.

LORENZ, Federico. "Otras marcas. Guerra y memoria en una localidad del sur argentino (1978-1982)”. En: BOHOSLAVSKY, Ernesto et. al., Problemas de historia reciente del Cono Sur. Buenos Aires: Universidad Nacional de General Sarmiento, Universidad Nacional de General San Martin. Tomo 1, 2011.

MARCHESI, Aldo. "La partida decisiva de la revolución en América Latina". Militantes bolivianos, chilenos y uruguayos en la Argentina peronista. Buenos Aires, 1973-1976". Polhis. Dossier "El lugar de la "nueva izquierda" en la historia reciente, $\mathrm{N}^{\circ}$ 9, 2012, pp. 226-239.

MÁRMORA, Lelio. La amnistía migratoria de 1974 en Argentina. OIT, Documento de Trabajo. 1983. 
MONTERO, Lorena. La vigilancia de las Fuerzas de Seguridad a los exiliados chilenos en Bahía Blanca. La producción de inteligencia de la Sección Informaciones de la Prefectura Naval Zona Atlántico Norte (1976/1983), en IV Jornadas de Trabajo sobre Exilios Políticos del Cono Sur en el siglo XX. Bahía Blanca, 2018.

NOVICK, Susana. Política y Población. Argentina 1870-1989. Buenos Aires: CEAL, 1992.

PAREDES, Alejandro. Las condiciones de vida de los exiliados chilenos en Mendoza, 1973-1989. Tesis doctoral, Fahce, UNLP, 2007.

PEÑALOZA PALMA, Carla. Partir no siempre es sobrevivir. Refugiados del Cono Sur víctimas de la Operación Cóndor. En: HORVITZ, María Eugenia y PEÑALOZA PALMA, Carla (coords.). Exiliados y Desterrados del Cono Sur, 1970-1990. Santiago: Erdosain, 2016, pp. 203-224.

RODRÍGUEZ, Laura. Políticas educativas y culturales durante la última dictadura en Argentina (1976-1983). La frontera como problema. Revista Mexicana de Investigación Educativa, Vol. 15, º 47, (2010), 1251-1273.

SERRA PADRÓS, Enrique y SLATMAN, Melisa. Coordinaciones represivas en el Cono Sur de América Latina (1964-1991), Taller (segunda época) Revista de Sociedad, Cultura y Política en América Latina, Vol. 1, № 1, pp. 27-32, 2012.

SERVETTO, Alicia. 73/76. El gobierno peronista contra las 'provincias montoneras'. Buenos Aires: Siglo XXI, 2010.

TORRES, Susana. "Un viaje de idas y vueltas. Imágenes y prejuicios en la construcción de las identidades chilenas en Comodoro Rivadavia", Revista Hermeneutic, N 8, 20009.

\section{Fuentes documentales}

B.O. (Boletín Oficial de la República Argentina). Ley 17.401, 22 de agosto de 1967.

B.O. (Boletín Oficial de la República Argentina). Ley 20.840, 2 de octubre de 1974. 
B.O. (Boletín Oficial de la República Argentina). Ley 21.259, 26 de marzo de 1976. B.O. (Boletín Oficial de la República Argentina). Ley 21.610, 5 de agosto de 1977. B.O. (Boletín Oficial de la República Argentina). Ley 22.439, 27 de marzo de 1981. B.O. (Boletín Oficial de la República Argentina). Ley 20.835, 13 de diciembre de 1974

Comisión Coordinadora de Acción Social, "Informe para la reunión plenaria del 14 de septiembre de 1977”, 1977. Archivo CAREF

DNM, Nota 119/83 al Sr. Jefe del Departamento Organismos Internacionales, Ministros Atilio N. Molteni, 1983. Archivo desclasificado de la Cancillería Argentina

RECEBIDO EM: 26/08/2019 APROVADO EM: 16/10/2019 